\title{
Uso experimental de 6LowPAN em redes BLE
}

\author{
Maicon Zanella ${ }^{1}$, Mauricio Santos ${ }^{1}$, Rafael Piccoli ${ }^{1}$, Samuel F. Ferrigo ${ }^{1}$ \\ ${ }^{1}$ Centro Universitário UNIFTEC \\ Caxias do Sul - RS - Brasil \\ \{maicon.zanella, mauricio.silva,rafaelpiccoli, samuelferrigo\} \\ acad.ftec.com.br
}

\begin{abstract}
Bluetooth Low Energy is a new technology that enables communication of verylow energy devices. The project intends to create a connection between BLE devices, addressing the interfaces with IPv6 through the 6LowPAN protocol. The model evaluation is performed by connection simulations between a Raspberry Pi 3 (Model B) and a Linux notebook, testing them to the protocols ICMP, HTTP, FTP, Telnet, SSH, VNC and SMB.
\end{abstract}

Resumo. O Bluetooth Low Energy é uma nova tecnologia que permite a comunicação de dispositivos de baixíssimo consumo energético. O projeto pretende criar uma conexão entre dispositivos BLE, endereçando as interfaces com IPv6 por meio do protocolo 6LowPAN. A avaliação do modelo realizada por simulações da conexão entre um Raspberry Pi 3 (Model B) a um Notebook Linux, testando-os aos protocolos ICMP, HTTP, FTP, Telnet, SSH, VNC e SMB.

\section{Introdução}

O Bluetooth é um padrão global de comunicação sem fio e de baixo consumo de energia que permite a transmissão de dados entre dispositivos, desde que um esteja próximo do outro. Sua utilização vem crescendo significativamente se tornando muito popular, evoluindo de forma rápida. Atualmente existe uma série de desafios para aprimorar a utilização dessa tecnologia, com a popularização da internet das coisas, também conhecida como IoT, vem ocorrendo uma mudança radical na forma de pensar neste segmento no mercado, exigindo uma busca pela conectividade de dispositivos cada vez maior [Ferrigo et al. 2017].

O BLE é uma evolução do bluetooth tradicional, onde seu consumo de energia é muito menor [Ferrigo et al. 2017], aumentando a autonomia da bateria. O trabalho visará uma análise referente a conectividade de dispositivos utilizando o protocolo 6LowPAN, possibilitando a integração dessa arquitetura com a TCP/IP. Assim abre-se a possibilidade de uso desse protocolo em outras aplicações, como ICMP, HTTP, FTP, Telnet, SSH, VNC e SMB [Schrickte 2013].

O objetivo da análise está voltado em viabilizar a realização de testes dos protocolos citados acima, em uma rede BLE sobre o 6LowPAN, comparando algumas características destes com o seu uso em uma rede Wireless, verificando questões como latência, desempenho, atividade, limitações, entre outros utilizados no estudo de caso. 


\section{O Bluetooth Low Energy (BLE)}

O BLE é o nome utilizado em dispositivos Bluetooth 4.0 ou superiores. Em comparação à versão anterior, a conexão em BLE fica a maior parte do tempo em standby, o que faz a autonomia da bateria aumentar [Lindh et al. 2017].

A sua versão mais recente (5.0) traz algumas melhorias, como o consumo de energia que é reduzido entre $50 \%$ e $90 \%$ se comparado com o Bluetooth clássico [Eichner et al. 2020]. Nessa versão, além da eficiência energética, a capacidade de transmissão de mensagens aumentou, além de uma maior eficiência de transmissão e distância de alcance.

A camada superior é utilizada por aplicações na qual geralmente são os servidores. Nela estão os protocolos principais do BLE como o Generic Attributes Profile (GATT) e o Generic Access Profile (GAP). Esses protocolos são responsáveis pela comunicação entre cliente e servidor. A camada de enlace é onde os dispositivos enquadram os dados para posterior transmissão aos demais dispositivos BLE. Essa camada trabalha com cinco estados que definem a situação de um dispositivo BLE [Gupta 2016], são eles: inativo, anúncio, escaneamento, inicialização e conexão. A camada de enlace também define o formato do quadro para transmissão pela camada física. A camada física encontra-se na base da arquitetura. Ela é responsável pelo rádio e pela transmissão e modulação da frequência de transmissão.

$\mathrm{Na}$ arquitetura há um protocolo muito importante, chamado L2CAP. Ele é responsável pela compactação dos cabeçalhos oriundos das camadas posteriores para a camada de enlace [Priess et al. 2003], fracionando pacotes e encaminhando ao dispositivo receptor, conforme apresentado na Figura 1. No 6LowPAN, o L2CAP é responsável pela fragmentação de pacotes IPv6 em quadros suportados pela camanda de enlace do BLE.

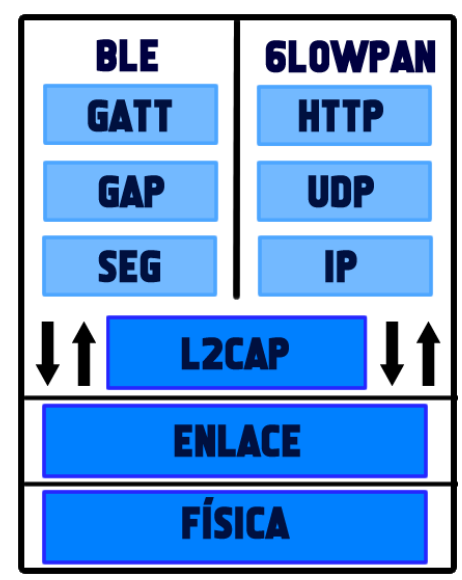

Figura 1. Estrutura do BLE tradicional e do BLE com uso de 6LowPAN. Fonte: Elaborado pelo autor.

O 6LowPAN é um protocolo que está abaixo do protocolo IPv6 e é uma alternativa para gerar integração entre o padrão IEEE 802.15.4 com o IPv6 [Ferrigo et al. 2017]. Ele também é responsável por converter os pacotes IPv6 em quadros suportados pela camada de enlace do BLE. 


\section{O Laboratório}

Como parte do estudo de caso, serão utilizados os seguintes dispositivos: um Raspberry Pi3 (Model B) com processador 1.2GHz 64-bit quad-core ARMv8 CPU, 1GB de RAM com sistema Raspbian OS com a versão 4.19 do Kernel Linux; e um Notebook com processador 1.7GHz 64-bit Intel Core i5-3317U, 8GB de RAM com sistema operacional Ubuntu 18.04 com a versão 5.0 do Kernel Linux. Ambos dispositivos comunicam-se através de um enlace 6LowPAN/BLE.

Para teste do cenário, foram analisados os seguintes serviços: ICMP, HTTP, FTP, Telnet, SSH, VNC e SMB.

\begin{tabular}{|l|l|l|l|}
\hline Protocolo & $\begin{array}{c}\text { Conexão } \\
\text { Completa }\end{array}$ & $\begin{array}{c}\text { Conexão } \\
\text { Parcial }\end{array}$ & $\begin{array}{c}\text { Sem } \\
\text { Conexã̃o }\end{array}$ \\
\hline ICMP & & & \\
\hline HTTP & & & \\
\hline FTP & & & \\
\hline TELNET & & & \\
\hline SSH & & & \\
\hline VNC & & & \\
\hline SMB & & & \\
\hline
\end{tabular}

Figura 2. Resultado dos testes de conexão. Fonte: Elaborado pelo autor.

\section{Resultados}

Conforme demonstrado na Figura 2, o protocolo SSH não obteve conexão, os protocolos HTTP, FTP e SMB obtiveram uma conexão com sucessivas quedas do enlace, chamada de conexão parcial, e os protocolos ICMP, TELNET e VNC obtiveram conexão sem apresentar qualquer tipo de problema.

Para o protocolo ICMP foram realizadas três baterias de testes, com 50, 100 e 200 pacotes utilizando o comando ping na rede BLE/6LowPAN e o mesmo processo foi repetido para a rede Wireless IEEE 802.11ac. Pode-se observar na Figura 3 a comparação entre a primeira bateria de testes realizada com o envio de 50 pacotes ICMP. É possível notar que na rede Bluetooth a latência oscila em um range menor, variando de $46 \mathrm{~ms}$ a 198 $\mathrm{ms}$, e não perde pacotes, porém possui uma latência média de $72 \mathrm{~ms}$, valor que representa mais que o dobro da rede wireless, com $34 \mathrm{~ms}$.

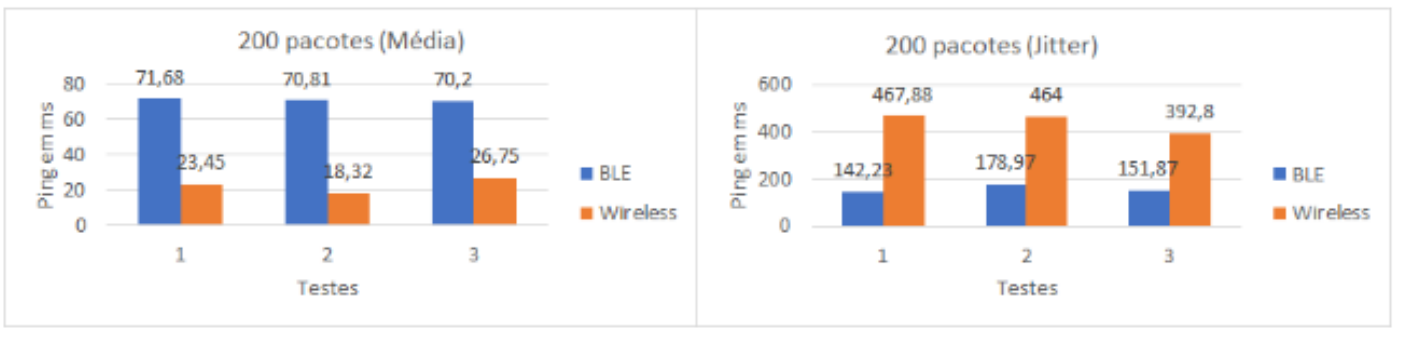

Figura 3. Comparação da primeira bateria de testes. Fonte: Elaborado pelo autor. 
É possível observar na Figura 4 os resultados obtidos na bateria de testes com 200 pacotes enviados em cada rede e notar a diferença entre elas. Primeiramente, percebe-se que a rede BLE/6LowPAN mais uma vez apresenta um jitter menor em relação a rede IEEE 802.11. Além disso, não ocorreu perda de pacotes em nenhum dos 9 testes realizados na rede BLE/6LowPAN, enquanto que na rede IEEE 802.11 houve uma perda de $2 \%$ dos pacotes, demonstando que a primeira é uma rede mais estável se comparada com a segunda.

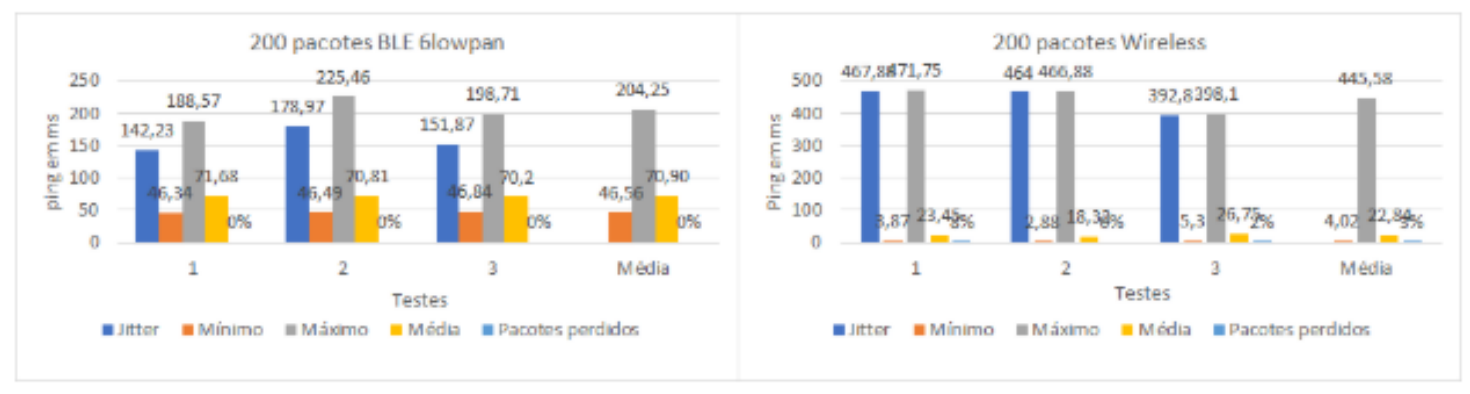

Figura 4. Comparação da segunda bateria de testes. Fonte: Elaborado pelo autor.

\section{Conclusão}

A partir dos resultados obtidos, pôde-se perceber que algumas aplicações com menor throughput são suportadas pela rede BLE aplicando o 6LowPAN. Nas conexões onde o tráfego de dados é maior, a placa Bluetooth era sobrecarregada e a conexão era finalizada nos testes realizados.

Os testes realizados em laboratório trouxeram resultados interessantes, especialmente no que diz respeito à estabilidade da rede BLE/6LowPAN. Ainda, constatou-se a viabilidade de utilização do IPv6 em equipamentos BLE em alguns seviços convencionais de uma rede TCP/IP.

\section{Referências}

Eichner, A., da Silva, N., and Rizzetti, T. A. (2020). Definindo um protocolo de autenticação utilizando bluetooth low energy para dispositivos no conceito de iot. In Anais da XVII Escola Regional de Redes de Computadores, pages 97-104. SBC.

Ferrigo, S. F., da Costa, C. A., and da Rosa Righi, R. (2017). Um middleware para gerenciamento de sensores de saúde corporais em dispositivos móveis. In Anais do IX Simposio Brasileiro de Computacao Ubiqua e Pervasiva. SBC.

Gupta, N. K. (2016). Inside Bluetooth low energy. Artech House.

Lindh, J., Lee, C., and Hernes, M. (2017). Measuring bluetooth low energy power consumption. Application Note AN092.

Priess, W., de Rezende, J. F., Pirmez, L., and da Costa Carmo, L. F. R. (2003). Um mecanismo de escalonamento parametrizável para scatternets bluetooth. XXI Simpósio Brasileiro de Redes de Computadores, Natal.

Schrickte, L. F. (2013). Projeto, implementação e avaliação de desempenho de nós e gateway 6lowpan. Master's thesis, Universidade Federal de Santa Catarina. 